\title{
The Boer and the Jackal: Satire and resistance in Khoi orature ${ }^{1}$
}

\author{
Hermann Wittenberg \\ University of the Western Cape, South Africa \\ hwittenberg@uwc.ac.za
}

\begin{abstract}
Bushman narratives have been the subject of a large volume of scholarly and popular studies, particularly publications that have engaged with the Bleek and Lloyd archive. Khoi story-telling has attracted much less attention. This paper looks a number of lesser known Khoi narratives, collected by Thomas Baines and Leonhard Schultze. Despite commonalities in the respective oral traditions, Khoi folklore appears more open to discursive modes of satire, mockery and ridicule, features which are not readily found in Bushman story telling. A number of Khoi narratives that feature the trickster figure of the jackal are presented and analysed as discursive engagements with historical realities and political forces that impinged on indigenous societies. It is argued that Khoi orature was able to mock and subvert settler dominance by making imaginative use of animal proxies such as the jackal. This capacity for satire in Khoi oral culture allowed it to resist colonial violence on a discursive level, a strategy that was much less pronounced in Bushman narration.
\end{abstract}

Key words: Bushman narratives, Khoi orature, satire, resistance, subversion of settler dominance.

\section{I}

\begin{abstract}
A lthough considerable scholarly and popular attention has been focused on Bushman narratives over the last 30 years, much of it centred on analyses and re-tellings of the Bleek and Lloyd archive, ${ }^{2}$ little attention has been paid to Khoi story-telling and the comparative insights made possible by such a study. The monumental work on the |Xam carried out by Wilhelm Bleek and Lucy Lloyd in the 1870s and 1880s has overshadowed Bleek's own earlier studies of Khoi folklore. Soon after his arrival in Cape Town and appointment as Lord
\end{abstract}

Grey's librarian, Bleek started to solicit Bushman and $\mathrm{Khoi}^{3}$ folktales from missionaries stationed in the remoter areas of the colonies, and in 1864 a collection of 42 of these translated oral narratives was published as Reynard the Fox in South Africa; or Hottentot Fables and Tales. The book is South Africa's earliest publication of indigenous literature, and it remains one of the most important collections of Khoi orature. This paper has two interrelated interests: firstly, drawing attention to the largely neglected area of Khoi orature, and secondly, developing an argument about the similarities and differences between Khoi story-telling 
and Bushman narratives. It is in this context that the contradistinctive idea of satire will be explored. In Khoi orature, satire is associated with the transgressive trickster figure of the jackal; he is attractive, roguish and able to outwit the powerful, in particular predators such as lions. In |Xam story telling on the other hand, the jackal does not function as a likable trickster but has negative traits such as cunning, cowardice and selfishness, qualities that have not allowed him to become a figure of identification. Such a bifurcation, this paper will suggest, was not without political consequence in the often violent nineteenth century Cape frontier.

Given the long history of European contact with Khoi people at the Cape, contact that pre-dated the VOC settlement in 1652, it is surprising that more Khoi stories have not entered the colonial archive. Khoi self-representation in the form of a literary record is comparatively rare, despite the fact that they were South Africa's first indigenous people to come into contact with colonial literate cultures, a sustained and often intimate contact that stretched over 200 years from at least the late sixteenth century until the 1750 s when a coherent and distinctive Khoi culture disintegrated and became absorbed into the Cape underclass (Elphick 1985: xvii). Khoi languages persisted on the colonial fringes, such as the eastern and northern Cape, for another hundred years, but it is only in the remote Richtersveld and southern Namibia that one of the Khoi languages, namely Nama, is still spoken today. There is thus an almost inverse relationship between the long history of settler-native contact, and the volume of recorded narrative material, where we have the least number of records of Cape Khoi narratives, despite the extensive social history of pervasive and intimate interaction. The vast number of extant Khoi tales are drawn from more remote Nama and Koranna sources, as exemplified in Bleek's Reynard book, Leonhard Schultze's Aus Namaland und Kalahari (1907), L.F Maingaard's Koranna Folktales (1962), and the Sigrid Schmidt corpus (1989) assembled much later in southern Namibia. Schmidt's comprehensive Catalogue of Khoisan Folktales of Southern Africa (1989) lists mostly Nama Khoi narratives. The small number of Cape Khoi sources cited in her bibliography are in publications mainly devoted to other concerns (such as hunting, natural history and travel), with the stories in them forming a minor aspect.

The paucity Cape Khoi folklore and their incidental presence in the record may be ascribed to the late emergence of folklore as an object of scholarly study in the nineteenth century. Drawing on the philosophy of Herder and the philological work of the Grimm brothers, researchers in the emerging field of folklore studies in Europe sought to discover an authentic literary heritage that would reveal a people's essential and distinctive national character, uncontaminated by the homo-genising forces of urban capitalist modernity (Bendix 1997). Such a paradigm, locating national and ethnic authenticity in a rural and primitive past, could readily be transferred to the colonial arena. This explains the interest of Bleek, Grey and other Cape intellectuals in collecting, studying and systematising indigenous literature. By the time that folklore had emerged as a distinctive area of scholarly interest, Cape Khoi culture and language had largely disappeared. Cape Khoi literature is consequently very rare in the colonial record. With that in mind, we need to consider the significance of the stories collected by the famous painter Thomas Baines. Baines was born in England in 1820 and came to South Africa as a young man to embark 
on a career as explorer artist. He travelled widely throughout the region, reaching as far north as the upper parts of the Zambezi on an expedition led by David Livingstone. His prolific output of sketches and dramatic oil paintings remains the most valuable pictorial Africana of the nineteenth century. The Cape Khoi stories recorded by Baines were likely to have been picked up in the course of his many travels, possibly during his early four-year stay in the Eastern Cape in the 1840s (Carruthers and Arnold, 1995).

The two Cape Khoi stories which Baines reproduced from his recollections were published in the little-known and short-lived Folklore Journal, which published over 12 issues in 1879 and 1880 . Issued by the South African Folklore Society, in which Lucy Lloyd was an influential member, the Folklore Journal must rank as the first scholarly journal published in the country, in any discipline. Under its epigraph 'Semper novi quid ex Africa' (Always something new out of Africa), it sought to make available 'a representative collection of traditional literature existing among South Africa's aboriginal races', which were 'rapidly passing away, under the influence of European ideas, and the spread of European civilisation' ('Preface' 1879: ii). The scientific ambitions of the journal were discernible in the language of the preface: it wanted to collect 'specimens of Native literature' drawn directly 'from the lips of the aborigines, written down in their own language and words, and accompanied by a translation into English' ('Preface' 1879: ii-iii). The journal accordingly pioneered the columnar side-by-side printing of oral transcribed material and translations used in the subsequent publication of Lucy Lloyd's famous Specimens of Bushman Folklore (1911). The journal also contains a number of significant contributions, among them |hanłkass'o first kumkummi in print (the stories 'The Wind' and 'The Son of Wind'), as well as Wilhelm Bleek's posthumously published proposal to establish an anthropological institute in the region.

The Folklore Journal, together with more popular publications such as the Cape Monthly Magazine, must be understood as part of a short-lived Cape liberal enlightenment, a period between 1850 and the 1870s during which colonial intellectuals drew on universal knowledge and science to articulate more tolerant and open-minded attitudes towards indigenous people. As described by Saul Dubow in his study $A$ Commonwealth of Knowledge: Science, Sensibility and White South Africa (2009), the demand for mining labour and the more assertive demands of settler agriculture militated against the liberal racial attitudes of an urban educated elite after the discovery of diamonds in Kimberly in 1868 and self-government in 1872 .

Two of Baines's Cape Khoi stories were published in the Folk-lore Journal, namely 'The Story of a Dam' and 'The Lion and the Jackal, A Hottentot Story'. Both are jackal trickster stories, of a type well known from other sources. The lion and the jackal story is found in similar form not only in the Bleek and Lloyd corpus (a story told by $¥$ kasin 'The lion and the jackals' (Lewis Williams 2000: 165)), but also in the Reynard volume, as well as the Schultze collection. The story is briefly as follows: the lion and the jackal agree to hunt together and share the spoils, with the jackal volunteering to 'transport the game to their dens', taking 'care that Mrs Lion and her family should not want'. The hunt is exceedingly successful, but when Lion returns home, his family is 'on the point of death from sheer hunger, and in a mangy state'. The jackal, it appeared, had only given them a few entrails of the game'. Lion 
is in 'a terrible fury, vowing death to the jackal and his family', but the jackal had taken the precaution of ensconcing himself and his family on top of a steep 'krantz'. When the vengeful lion arrives, the jackal greets him with the innocuous words, 'Good morning, uncle.' The lion responds in fury: 'How dare you call me uncle? You impudent scoundrel!' The jackal pretends to be taken aback, and blames his wife. Taking a stick, he beats a hide loudly while Mrs Jackal screams as instructed. Her howls are so dismal that the lion begs the jackal to be merciful. Having mollified the lion, the jackal then asks him to come up and eat meat, but the cliff is too steep, so he cannot. The jackal then offers to haul him up with a 'riem' (rope). Just as the lion nears the top, the jackal lets go of the rope, so that the lion falls down. Jackal repeats the process of pretending to blame and beat his wife. Then he again invites lion to come up and eat meat. Once more the lion falls, on this occasion 'with such force, that he was fairly stunned for some time'. After the lion recovers, the jackal suggests in a most sympathising tone' that he drop down a 'nice fat piece of eland breast' into the lion's mouth. However, instead of meat, the jackal takes a round stone and heats it in the fire till it is red hot. Then he puts fat around it. He drops 'the hot shot right into the lions capacious mouth, which ran through the poor beast, killing it on the spot' (Baines 1880: 54-57).

In the Baines version, the story has been somewhat domesticated, as is evident in the Victorian language and metaphors (the hide is 'belaboured', the stone is equated with 'hot shot', etc.), making it clear that the story was not the result of a scholarly attempt to collect folklore (as was Bleek's Reynard volume) or the outcome of ethnographic fieldwork (as in Schultze 1907, Schmidt 1989). Nevertheless, it presents us with one of the earliest and best elaborated jackal trickster narratives, showing clear linkages in oral tradition between the Cape Khoi and the more northern Nama cultures. If we compare the Baines story with the Nama jackal stories collected in Bleek's Reynard volume, we can see that both the Nama and Cape Khoi stories contain the same elements (unequal division of meat, an unreliable riem, an unclimbable cliff, a hot stone dropped into the lion's mouth).

However, both Baines's and Bleek's narratives illustrate the 'processes of exclusion, occlusion and effacement that have occurred in the construction of the cultural history of this country', as Duncan Brown argues in his introduction to Oral Literature and Performance in Southern Africa (1999: 4). As shown elsewhere (Wittenberg 2012), Bleek suppresses the disruptive, erotic and scatological elements of indigenous narration that he deems unsuitable for a Victorian reading public. As Bleek himself put it in the preface,

to make these Hottentot fables readable for the general public, a few slight omissions and alterations of what would otherwise have been too naked for the English eye were necessary. (1864: xxiii)

While Bleek may have been motivated by a Victorian reserve that could not entertain Rabelaisian material, we also need to see his editorial interventions in the light of progressive Cape liberal attempts to disassociate the stereotypical figure of the 'Hottentot' from its well-established negative associations in colonial Cape discourse with disorderliness, idleness and licentiousness. Overall though, Bleek's renditions of Khoi folklore need to be understood as limiting versions of indigenous orature. 


\section{II}

The inherent sanitisation of nineteenth century Khoi orature becomes particularly apparent when comparing the Bleek and Baines narratives with oral material collected by the German ethnographer Leonhard Schultze, published in Aus Namaland und Kalahari (1907). Schultze's 67 tales were collected during extended field trips in the northern Cape and southern Namibia. While Schultze's scientific work became entangled with and tainted by his involvement in imperial Germany's notorious Herero and Nama wars of extermination (see Wittenberg 2012), his fluency in Nama, and his rigorous fieldwork methodology of transcription produced a qualitatively different body of narratives:

What I had listened to at night around the fire, I had repeated to me slowly the next day by the story teller, so that, after some practice, I was able to obtain a coherent dictation. In order to ascertain if the act of dictating had disturbed the sentence structure and sequence, I asked the Hottentot to repeat his story at normal speed and carefully noted down variations. (1907: 752)

Schultze's corpus of tales was thus collected in more natural conditions than those in which Bleek did his research on ex-prison convicts, and yielded stories that contained a fair share of risqué jokes, scatological references and politically disruptive material. Commenting on Bleek's stories, Schultze claimed that they 'do not reveal to me the Hottentot whom I have gotten to know. Since I was able to tap into the very source of their lore, I will disregard his versions completely' (1907: 389).

Schultze's Khoi stories, as will become immediately apparent, are told in a very different register from that of the
Baines stories as well as Bleek's Reynard tales in which the 'naked' elements of indigenous storytelling had been censored. In Schultze's analogous story 'Der Löwe und der Schakal' (1907: 489-490), the narrative unfolds in much the same sequence, though elements are localized in order to adapt to different fauna and topographic conditions. For instance, instead of an eland, a giraffe is the object of the hunt, and the rocky krantz is replaced by a camelthorn acacia tree. The narrative outcome (the lion is killed by being duped into swallowing a hot stone) is common to all the versions, but in the Schultze narrative there is an additional small 'naked' or bawdy, graphic detail: the hot stone tore apart the lion's anus as he was trying to 'shit' it out. Hence, as was explained to Schultze by his informant, lions will to this day always eat a piece of skin first, before wolfing down the meat, so as to plug up the hole.

In another lion and jackal tale in Schultze's corpus, 'The Lions who pretended to be dead", the transgressive humour with similar 'naked' elements is even more evident:

Two lions who were travelling were tired and they saw a jackal approaching. [Not wanting the trouble of a hunt] they lay down pretending to be dead, and the jackal came closer. He quietly crept up and softly touched the back hole [anus] of the one lion, and saw how it contracted. Then he knew that they only pretended to be dead and said: "Thank you Lord, that you have given me this food!" Then he made a fire with some grass and said aloud: "Let me first find some fire wood," and he went off. And while he was breaking off wood, he gradually went further and further away, and once he had escaped he climbed on to a rock and called out: "Luckily I touched your arseholes! You stupid, dirty, pus-encrusted dick 
heads! You could have almost killed me!" This is how he shouted, but the lions were very tired, and therefore they did not run after him. (Schultze 1907: 486)

Here the jackal avoids being eaten through a neat bodily inversion when he approaches the lion from the wrong end: instead of being ingested by the lion's dangerous mouth, he cunningly approaches from the other side, exploiting the unguarded weakness of the master's delicately twitching anus. In Achille Mbembe's discussion of scatological humour as political strategy in the African postcolony, 'the significance of orifices' and of a body that drinks, eats, shits 'and is open' is fundamental to 'people's political humour' (2001: 107), a humour which in particular targets 'the president's anus' (2001: 108). Both these Khoi tales may very well function in a similar subversive manner in their mockery of the 'king of the beasts' as they disallow faunal and political elites to eat easily at the cost of others, and skilfully deconstruct the lion's greed (figured by his ravenous, everhungry open mouth) by shifting attention to his vulnerable anus. As we have seen, in Khoi orature the wily jackal is an attractive and entertaining trickster figure who consistently manages to outwit the powerful and mighty by exploiting their vulnerabilities. In these narratives, the jackal is clearly a figure of identification for Khoi story-tellers and listeners, while the lion is the symbolically defeated and discredited enemy at whose misfortune one laughs. The cultural script implicit in the jackal trickster narratives allowed the weaker subject to outwit a dominant master. I would argue that this was a template that seemed eminently adaptable in the face of historical change. With the entry of powerful colonial forces into the northern Cape frontier, the Khoi could deploy their jackal trickster narratives as a strategy of discursive resistance. But before we examine the political consequences of such story-telling modes as symbolic forms of resistance, we first need to examine the parallels in Bushman orature.

\section{III}

In Bushman culture, the lion, as in Khoi orature, has a negative connotation so we can speak of a considerable cultural overlap. As Mark McGranaghan has shown in a detailed study of |Xam society, identity and the idea of the human was not restricted to homo sapiens but was fluid and expansive enough to encompass other 'people' such as animals. However, lions were 'people who are different' since they 'eat other people', and display no restraint in their excessive consumption:

Anti-social agents were for the |Xam fundamentally "different", violent and angry "beasts-of-prey" who went about by night to kill people (LL.II.3.421-422) and eat them (LL.II.16.1550)... The most typical exemplars of persons who did not act in accordance with these norms and aims of |Xam society were to be found (unsurprisingly) in nonhuman communities such as those of lions (or "beasts-of-prey" generally) (2012: 211; 204-205)

In |Xam culture, the lion was thus not only a dangerous marauder who posed a real and ever-present danger, but was also an exemplary figure for predatory anti-sociality, violating the accepted social norms of 'behaving nicely' (2012: 183) and sharing food with others. People who displayed such qualities of greed or violence were regarded as 'different' (|xarra) and equated with lions (|xa), where the lexical similarity reinforced an overlap in meaning. 
The negative treatment given to lions in both Khoi and |Xam orature points to a pan-Khoisan cultural world. Megan Biesele's Kalahari based work, for example, argues that 'Bushman folklore is itself practically indistinguishable from Khoisan tradition as a whole' and that it 'is very hard to tell the difference between a Bushman story and a Khoikhoi story' (1993: 34). Biesele's work points to the commonalities in pan-Southern African Khoisan culture, citing close similarities and linkages between |Xam stories published in Bleek and Lloyd's Specimens of Bushman Folklore (1911) and narratives collected among the Kalahari Ju |'hoa during the 1970s. But assumptions of an undifferentiated cultural commonality across diverse Southern African Khoi and Bushman societies are also problematic, given the pronounced differences between them in economic mode; Bushmen or San were generally associated with a hunter-gatherer life-style and the Khoi were pastoralists. Earlier studies, such as Richard Elphick's (1977) influential materialist thesis, underplay the role of intrinsic ethnic and cultural differences, arguing that many of the people whom the colonists called Bushmen and the Khoi called San (both pejorative terms) were failed pastoralists who had fallen on hard times, lost their livestock and now had to rely on hunter-gathering; conversely that people who were pastoralists were former hunter-gatherers whose economic fortunes had now risen. The difference between the Cape hunter gathers and Khoi pastoralists was thus fluid and contingent on historical change, with the people concerned moving between two different economic modes.

Elphick's study which discounted differences between hunter gatherers and pastoralists was important in destabilising essentialist notions of a pure and pristine hunter-gatherer Bushman culture that lived in isolation from historical change. But more recent studies have re-asserted the importance of fundamental cultural differences between hunter gathering and pastoral societies, differences that are keyed to economic differentiation. Mark McGranaghan argues that while hunter gathering was not an absolute and exclusive mode for the |Xam (for example Bleek's informant Dia!kwain possessed cattle), there were 'meaningful distinctions between hunter-gatherers who have acquired livestock or started cultivating wild plants, and pastoralists or farmers who happen to hunt or who supplement their diet with wild plants' (2012: 339). John Parkington has proposed that hunter-gatherer and pastoralist world-views and ideologies were fundamentally divergent and incompatible, making a pragmatic cycling between two modes of economic subsistence highly unlikely. Bushman culture is inclusive and fundamentally shaped by an obligation to share, which not only solves the problem of waste in times of a sudden surplus of fresh food, but also permeates all other aspects of culture. The eland, whose successful hunt was productive of a huge supply of meat far in excess of the needs of the hunter and his family, is so central in Bushman rock art and narrative precisely because it represented an exemplary instance of this ideology of sharing, the basic social glue of huntergatherer society. While Bushman culture is dispersive, distributive and egalitarian, Khoi pastoral culture, in contrast, is exclusive and accumulative, based on property ownership and fairly well developed hierarchical political systems. As Parkington puts it: '[H]erders or farmers who lost the ability to herd or grow crops may well have engaged in hunting and in the gathering of wild plant foods, but never lost the world-view of the accumulator' (2007: 86). 
If we follow this argument, Khoi and Bushman cultures enjoyed commonalities shaped by distant ancestral links, by centuries of contact and by living in the same landscape, but they were also fundamentally divergent in ideological orientation or world view. I would suggest that in the oral story-telling traditions, these differences were articulated in the way the jackal trickster figure could be used. So while Khoi and |Xam beliefs coalesced with respect to lions, they were sharply different with regard to jackals. Jackals, as we have seen, were sympathetic figures with which the Khoi identified, proxies for the human underdog in his dealings with powerful and oppressive masters. But in |Xam culture, jackals, like lions, were also primarily regarded as predators or 'different people'. As McGranaghan has shown, the idea of a greedy person was 'applied to animals (e.g. jackals, LL.II.15.1477) ${ }^{4}$ and people (LL. II.14.1319) noted for generally excessive consumption' (2012: 183). In a culture whose survival was premised on an ideology of distribution and sharing, such greediness was not permissible: 'people should work the excess food 'nicely' instead of behaving like jackals by gorging themselves while food was plentiful (LL. VIII.16.7449')' (2012: 254). In the Bleek and Lloyd archive, jackals thus function very differently in Khoi story-telling. Here they are generally associated with negative traits such as cowardice, cunning and selfish behaviour. According to |hanłkass'o, the places where jackals and hyenas urinate must be avoided (LL VIII.29. 8584 rev.-8587 rev.), and they are also associated with dangerous black clouds ('jackal clouds') from which one should shelter (LL VIII.-23. 8018-8029). He also warns that children should not eat its heart lest they imbibe his cowardly qualities (LL VIII-16. 7457-7459).

If we accept that the |Xam held such sceptical and negative views of jackals, how do we then make sense of a Xam trickster narrative which appears to violate this cultural logic, and depicts the jackal as a hero? The story in question is łkasin's tale, 'The lion and the jackals', related to Lucy Lloyd in November 1873. In this story, a jackal shoots eland on two successive days, but always loses his kill to a lion. A sorceress advises him to remain silent and stay at home; she then makes all the bushes and water disappear so that an eland comes right up to his house. The jackal shoots the eland, and the sorceress makes a mountain rise up with the dead eland upon it, together with all the other houses, water and 'also the people' (Lewis Williams 2000: 165). The lion, smelling the feast above him, wants eland fat poured into his mouth and the jackal, with the help of other jackals, heats a stone and drops it into the lion's mouth below. His insides are burned up and he dies while running away. The story ends with all the jackals looking at the dead lion, the first jackal saying 'The man is dead' (Lewis Williams 2000: 166).

At first glance the story is similar to the Khoi versions of Baines, Bleek and Schultze, but there are important differences, most significantly the supernatural element of the sorceress is added. Overall, the resourceful, cunning trickster personality of the jackal is disabled in $\neq$ kasin's story and he is strangely passive in the face of the lion's rapaciousness. Agency is less located in a wily animal than in the supernatural agency of the sorceress through whose divine intervention social justice is eventually meted out. Although the story contains the basic plot structure and several narrative elements of the Khoi jackal trickster stories (dispossession of the game, refuge in a high place, a hot stone wrapped in fat), 林in's version of the narrative destabilizes its ostensive Khoi trickster structure and instead refashions the tale as a narrative permeated 
by the |Xam ideology of distribution and sharing, as is evident in the co-operative actions of the jackal community on the cliff:

He went and said to the other jackals, 'The lion is asking us for fat.' The other jackals told him to get a stone, and they all heated it. Another jackal took the stone, and they all heated it. The first jackal went and told the lion to wait. He went back and asked the other if the stone was heated. The others said yes. They took the stone out of the fire. The others told him to take fat from the pot which was on the fire and to fill up the dish.... Another jackal held the wet eland's skin. (Lewis Williams 2000: 166)

The narrative clearly emphasises a multiplicity of actors engaged in communal action and co-operative behaviour, rather than individual heroic action, as in the conventional trickster tales. The hybrid nature of the tale (Khoi fabula, |Xam sjuzhet) and its anomalous relationship with other representations of jackals in the |Xam corpus is possibly explained by the genealogy of its narrator: łkasin was the son of a Koranna chief and a |Xam mother and spoke both languages (Skotnes 2007: 220). łkasin went on to marry a |Xam wife and live with her community, and the hybrid nature of his story reflects a curious and revealing melding of two cultures. I am suggesting then that $\neq$ kasin took a well-known fable from his own Khoi pastoralist cultural background and re-shaped the narrative material to make it fit the ideological worldview of his adoptive |Xam community. The other jackal trickster fables in the Bleek and Lloyd archive, such as the stories 'The Jackal deceives the Hyena' and 'The Jackal and the Porcupine' are also drawn from Koranna sources and have undergone similar permutations.
The true trickster tales in |Xam orature are thus associated with the enigmatic |Kaggen or mantis figure whose mischievous presence both destabilises and reinforces social conventions, not the jackal. A good example is \|Kabbo's famous opening story in Specimens of Bushman Folklore, 'The mantis assumes the form of a hartebeest'. In this story the mantis disguises himself as a dead hartebeest, tricking the children to cut him up: "The children jumped for joy (saying): "Our hartebeest! we shall eat great meat" (1911: 23). But while they are busy dismembering the hartebeest, the pieces begin to move uncannily, eventually reconstituting themselves into the animal who chases the frightened children back home:

The children said: "We thought that the hartebeest's horns were there, the hartebeest had hair. The hartebeest was one which had not an arrow's wound; while the hartebeest felt that the hartebeest would talk. Therefore, the hartebeest came and chased us, when we had put down the hartebeest's flesh. The hartebeest's flesh jumped together, while it springing gathered (itself) together, that it might mend, that it might mending hold together to the hartebeest's back. The hartebeest's back also joined on.

Therefore, the hartebeest ran forward, while his body was red, when he had no hair (that coat of hair in which he had been lying down), as he ran, swinging his arm like a man.

And when he saw that we reached the house, he whisked round. He ran, kicking up his heels (showing the white soles of his shoes), while running went before the wind, while the sun shone upon his feet's face (soles), while he ran with all his might into the little river (bed), that he might 
pass behind the back of the hill lying yonder. (1911: 26)

The extract here is an example of the magical transformations of | Kaggen, the hybrid animal-human trickster. Like most of the Bleek and Lloyd material, the narrative is told in characteristic digressions, repetitions and reformulations in which the narrative retains an open-ended allusive nature that is resistant to a linear reading and to neat closure. Unlike the jackal trickster in Khoi orature, the | Kaggen figure is much less reducible to a human subject, and the tale as a whole remains located in a mysterious and enigmatic mythical space. Matthias Guenther writes that

Bushman mythology is hauntingly asocial and pre-cultural, as well as liminal and surreal. This expressive domain is removed from, rather than informed by, social reality; indeed social and cultural reality is frequently inverted or disassembled. The beings hovering above and tampering with that reality are therianthropic werecreatures or precariously human men or women whose ontological state is fragile and slippery, ever ready to undergo transformation back into an alternate state of being. (1994: 259)

In contrast to the mythic other-worldliness that makes the Bleek and Lloyd material so enigmatic, the Khoi tales, as we have seen, are more direct, earthy forms of story-telling in whose animal proxies we can easily recognize human characteristics. It is this groundedness and the social connection of the Khoi tales that makes it possible to adapted them more readily to changing historical circumstance, as is evident in following discussion.

\section{IV}

By the time that Bleek and Lloyd interviewed their informants in the late nineteenth century, |Xam society had already irrevocably disintegrated. After more than a hundred years of commando raids in which the IXam had become the target for genocidal extermination and enslavement, their hunting-gathering lifestyle had been severely curtailed by encroaching faming settlement in their dry northern Cape heartlands. Driven by starvation to enter the harsh service of farmers or risk arrest by engaging in stock theft, |Xam society was on the brink of dissolution (Bank 2006; Skotnes 2007). While the Cape Khoi society had earlier suffered a similar fate in the aftermath of a catastrophic smallpox epidemic in the early eighteenth century and consequently became assimilated into a hybrid Cape underclass, autonomous Khoi societies survived in the northern Cape regions of the colony. The Koranna waged successful wars against colonial encroachment in the mid 1860s (Penn 2005) forcing settlers to abandon the region, and the Nama retained a strong autonomous polity into the twentieth century until eventually crushed by General von Trotha's infamous annihilation warfare where they lost $50 \%$ of their population (Adhikari 2005: 317).

The Khoi oral tradition, particularly in the case of the Nama, reflects a resisting engagement with colonial power, where the narrative template of the jackal trickster fable was adjusted to deal with the new realities on the northern frontier. This was achieved through a simple substitution of the boer or white settler for the lion. The lion, as we have seen earlier, was associated in both |Xam and Khoi culture with rapacious and dangerous predatoriness. This substitutive association had a long cultural history as is evident in numerous colonial accounts. For example in his 1778 travel diary, Robert Gordon records 'Sunei' Bushmen as saying that 'they say we 
[colonists] are evil and come in the night like wolves [hyenas], and have hair like lions.' (quoted by McGranaghan 2012: 205). Boer commandos often attacked Bushman encampments at dawn, and the nocturnal habits of the enemy are further reinforced through the stereotypical figure of the bearded boer.

The connections between nocturnal, hairy predators (hyenas and lions) and powerful, hirsute settlers is a continuing cultural logic in the Khoi and Bushman imagination. In 2007, Jan van der Westhuizen, a member of the $¥$ Khomani group fighting SANParks for access to their ancestral hunting grounds in the Kalahari game reserve, used the motif of the jackal and the lion to illustrate the unequal power relations:

We have also had a tremendous struggle with the Parks. We call them the young male lion as he is a rich gentleman and we are the small jackals that just get a small bit of bread, or just wait for a small piece here and there of the bones or to scratch open the stomach contents once the young male lion is finished. And we ask that they ... give back to the people what was lost to them over all the centuries. (quoted in Dyll-Myklebust 2011: 141)

This association between lion and boer is evident in several of the tales in the Schultze and Schmidt corpuses, showing clearly that Khoi orature was able to adapt dynamically to historical and social change in a manner that sought to critique and challenge colonial power relationships. In one of these stories, 'The Jackal who sold a Horse to the Boers', the impish jackal outwits a greedy but dim-witted boer who eventually, once the penny has finally dropped, retaliates with characteristic and unrelenting violence:

The jackal sold a horse to the Boers but beforehand he put some money into the horse's back hole. He then led the horse to them and said: "Now I will first get some money from that horse!" And when the horse shat, he held his hand underneath, and they could see that the horse was shitting money.

When the two Boers spoke about the price of the horse, the jackal said: "I cannot put a price on this horse because I will not sell it. But any man would give me a wagon and its span of oxen for it."

The Boer gave him a wagon with a span of oxen. The jackal spanned in the oxen, climbed the wagon and said: "Boer, wait for three days and the horse will shit money!" Thus spoke the jackal and he rode away.

The two Boers however waited, and when the third day had passed, they waited until the fourth day. But the horse shat no money. Then they saddled their horses and gave chase. They came to a place next to the road and asked: "Where is the wagon that came past here?" "The day before he came past," they were told.

They rode on and came to another place and asked: "Where is the wagon that came past here?" And the people told them: "Yesterday it came past here."

They rode further and came to another place and asked: "Where is the wagon that came past here?" And the people told them: "This morning it came past here."

So they rode further and when they came to the jackal's place they called: "Uncle Fox, I will shoot you through your head!"

The jackal replied: "What have I done wrong that you want to shoot me?"

(C) Wittenberg and CMDR. 2014 
The Boer said: "You told me that the horse which does not shit money, shits money!"

But the jackal replied: "No, do not speak to me so rudely! My older brother traded with you, not I."

The Boers asked: "Where is he?" And the jackal replied: "There, further down that way is his place." So the Boers went away to the other jackal who was innocent in order to shoot him dead. (Schultze 1907: 470-472)

In stories such as this, the antics of animal proxies, who are thinly disguised human subjects, provide a window into the fraught colonial relationships between the settlers and the Khoi. Living on the fringes of a new colonial monetary economy, which was beginning to replace the traded exchange of goods, the Khoi here mock the greedy acquisitiveness of the settler by conflating money with 'shit'. The narrative also imaginatively inverts the more common-place historical realities where indigenous people were routinely duped by colonial settlers into unequal trade exchanges. In the early Dutch period, the Cape Khoi, for instance, bartered herds of oxen for a few nails, mirrors or other trinkets. In story-telling, a new inverted 'fictional reality' is manufactured through laughter and humorous consent which can rival or supplant their historical experience. The ending of the story is thus not necessarily readable as a retributive assertion of Boer power, but it could also be understood as a narrative mis-en-abyme: that the next jackal will also in turn outwit the Boer, and so on. Such 'discordant, unresolved endings of satiric texts can disrupt generic expectations' (1995: 15), according to Connert and Combe. The open-ended conclusion and lack of closure is a hall-mark of satiric narrative.
In the Schmidt corpus, such satire directed at settler authority proliferates and takes on even more extreme forms: in one tale, the jackal sells a flute to a boer which is claimed to have the power to resurrect the dead. The duped boer kills his wife, but the flute proves useless. In another violent story the jackal sets the farmhouse on fire, becoming lord over the white children; in another fantastical cross-dressing narrative the jackal disguises himself as a woman and becomes a serving maid in a boer household, using the opportunity to sleep with the Boer's daughter. When she falls pregnant, the duped Boer wants to kill the jackal, but he escapes (Schmidt 1989: 215). In such explicit, transgressive stories a counterhegemonic resistance is clearly visible, but the substitutive logic established in Khoi culture $($ Lion $=$ Boer $)$ would also imply that seemingly naïve lion and jackal fables would be understood to be referring to contemporary lived reality, with the outwitted lion becoming a symbol for the duped Boer.

\section{V}

An overall evaluation of Khoi satire shows that Edward Rosenheim's famous definition of satire is particularly apt. Rosenheim defined satire as 'an attack by means of manifest fiction upon discernible historic particulars' (cited in Ball 2003: 1). The victims or dupes of satire must therefore never be entirely fictitious, but always be recognisable figures in actual lived reality, as in the case of the Boers. The liberating comic potential of satire depends on such referentiality; the historic oppressor and the barely fictionalised target become merged. But satire is not simply reportage, but draws attention to its fantastical, absurd and at times grotesque aspects, an overt form of fictionalisation that shields 
its speakers from retribution. While satire seeks to associate the targeted figure of the dupe with 'discernible historic particulars', the genre as a whole makes use of an extravagant and at times burlesque form of fictionality that draws attention to its non-referential literariness. Just like the jackal, who can take the moral high ground and reject the Boer's accusation of 'speaking rudely', the Khoi story-teller can also shield behind the proxy figure of the crafty jackal and indulge in the fiction of simply telling innocent animal stories.

The deployment of the jackal in the Schultze and Schmidt corpuses suggests that Khoi orature was open to satirical and subversive discursive modes. However, based on the evidence of the Bleek and Lloyd records, the jackal trickster was absent in IXam orature. The jackal trickster, an impish, subversive figure of identification in the Khoi imagination, could therefore become enlisted in a postcolonial strategy of resistance where the settler could be symbolically outwitted and defeated. In the light of John Parkington's argument that Khoi society was already organised hierarchically long before the colonial intrusion into the Cape, we would expect that satiric modes of dissent could flourish in such a stratified social space and become transferrable to dealings with the colonial order. As Connert and Combe in their discussion of the genre put it, the primary function of satire is 'the process of unsettling hierarchies’ (1995: 15). Conversely, the absence of satire as a discursive resource in |Xam culture would be keyed to a more egalitarian, classless social order in which such discursive strategies would have had no purpose. Roger Hewitt, in his early seminal study of the |Xam archive, notes the limited discursive engagement of the |Xam with the violent settler order which was imposing itself on their land:
The dreadful conditions under which the |Xam lived at the time of the collection impinges only infrequently on the collected texts, and in only one narrative are the settlers even mentioned. (1986: 32)

Hewitt does not account for this ostensible gap in |Xam orature and one may also speculate that Bleek's and Lloyd's ex-prisoner informants may have been reticent about sharing their candid views of the European invader. This paper suggests that deeper rooted differences in culture, visible in the oral tradition, need to be taken into account when considering how |Xam and Khoi societies engaged the colonial order.

In conclusion then, the jackal stories show that the Khoi were able to deploy subversive humour, in particular mocking satire, as a cultural strategy in dealing with the powerful, and to adapt them to the challenges of living with and under the colonial intruder, whereas in IXam culture this repertoire of discursive accommodation was either not available or took different forms that are not readily visible in the Bleek and Lloyd archive. Bushman and Khoi orature has a large overlap in terms of similar narrative material, but the way in which the building blocks of story were narratively assembled, ordered and put to use was different. This difference, I have suggested, may lie in the different social and cultural structures of Bushman and Khoi societies, where a hierarchically stratified pastoral society, as in the case of the Khoi, may correlate with a culture in which mockery and satire flourished. These were cultural modes that were well suited to challenge the authority of the powerful and assert the agency of the weak, at least in an imaginary, fictional domain. In using animal proxies to mock the new Boer masters who were imposing their violent order on 
the Northern Cape region, the Khoi were thus able to reinvent an ancient but versatile figure in their folklore, the jackal trickster, and make him the imaginative vehicle for symbolic re-ordering of colonial power relations in which they, and not the Boer could emerge triumphant.

\section{ENDNOTES}

${ }^{1}$ The support of the National Research Foundation of South Africa (NRF) as well as the research fund of the University of the Western Cape is gratefully acknowledged. A much earlier, considerably different version of this paper was published in the South African Journal for Folklore Studies 22 (1): 1-13, 2012.

2 This famous archive of stories, personal testimony and paintings was assembled by the German philologist Wilhelm Bleek and his sister-in-law Lucy Lloyd in the 1870s. Their informants were /Xam prisoners who were serving sentences for stock-theft, murder and other offences in the Breakwater prison in Cape Town. What had originally been conceived of as a purely linguistic project to record a vanishing language, evolved into a massive and rich 12000 page record of a culture, its mythology and vanishing way of life. For a good general introduction see Neil Bennun's The Broken String. The Last Words of an Extinct People (2005), and Andrew Bank's careful historical contextualisation (2006). See also Pippa Skotnes's numerous publications, most recently Claim to the Country (2010).

${ }^{3}$ The use of racial terminology is complex and fraught in Southern African studies. The term "Bushman" instead of the term "San" is now again widely in use, though guardedly. I have also referred to the /Xam when my comments have been limited to this group. Instead of Bleek's and Schultze's use of "Hottentot", I have obviously used another less offensive term, choosing the generic, widely accepted word "Khoi", or Nama and Koranna when referring specifically to these Khoi groupings. Where I have used the synthetic term
"Khoisan" to refer to both Khoi and Bushman societies collectively, this does not imply that these two groupings are conflated.

${ }^{4}$ All direct references to the Bleek and Lloyd notebooks refer to the Digital Lloyd and Bleek resource, see Skotnes 2007. Most significant stories in the archive are published in Lloyd's Specimens (1911) and Lewis Williams's anthology (2000).

\section{REFERENCES}

Adhikari, Mohamed. 2008. 'Streams Of blood and streams Of money': New perspectives on the annihilation of the Herero and Nama peoples Of Namibia, 1904-1908,' Kronos: Journal Of Cape History 34: 303-320.

Baines, Thomas. 1879. The story of a dam. Folk-lore Journal 1: 69-79.

---. 1880. 'The lion and the jackal'. Folk-lore Journal 2: 54-57.

Ball, S. 2003. Satire and the Postcolonial Novel. London: Routledge.

Bendix, Regina. 1997. In Search of Authenticity: The Formation of Folklore Studies. Wisconsin: Wisconsin UP.

Bank, Andrew. 2006. Bushmen in a Victorian World: The Remarkable Story of the BleekLloyd Collection of Bushman Folklore. Cape Town: Double Story.

Biesele, Megan. 1993. Women like Meat. The Folklore and Foraging Ideology of the Kalahari Ju |'hoa. Johannesburg: Wits University Press.

Bleek, W.H.I. 1864. Reynard the Fox in South Africa, or Hottentot Fables and Tales. London: Trübner.

Carruthers, Jane and M. Arnold. 1995. The Life and Work of Thomas Baines. Cape Town: Fernwood Press.

Connert, B and K. Combe (eds). 1995. Theorising Satire: Essays in Literary Criticism. New York: St Martin's.

Dubow, Saul. 2006. A Commonwealth of Knowledge: Science, Sensibility and White South Africa. New York: Oxford University Press.

Dyll-Myklebust, Lauren. 2011. 'Lodge-ical' 
thinking and development communication: !Xaus Lodge as a public-privatecommunity partnership in tourism. Unpublished PhD thesis, Durban: University of KwaZulu Natal.

Elphick, R. 1977. Kraal and Castle. Khoikhoi and the Founding of White South Africa. New Haven: Yale University Press.

Guenther, M. 1994. The relationship of Bushman art to ritual and folklore: In T. Dowson and D. Lewis-Williams (eds). Contested Images. Diversity in South African Rock Art Research. Johannesburg: Wits University Press. 257-274.

Hewitt, Roger. 1986. Structure, Meaning and Ritual in the Narratives of the Southern San. Johannesburg: Wits University Press.

Lloyd, Lucy (ed). 1911. Specimens of Bushman Folklore. London: George Allen and Unwin.

Lewis-Williams, D. 2000. Stories that Float from Afar: Ancestral Folklore of the San of Southern Africa. College Station: Texas A\&M University Press.

Maingard, L.F. 1962. Korana Folktales. Johannesburg: Wits University Press.

Mbembe, A. 2001. On the Postcolony. Berkely: University of California Press.

McGranaghan Mark 2012. Foragers on the frontiers. The |Xam Bushmen of the Northern Cape, South Africa, in the nineteenth century. Unpublished $\mathrm{PhD}$ thesis. Oxford: Oxford University.

Parkington, J. 2010. ॥Kabbo's sentence: In P. Skotnes. Claim to the Country. The Archive of Wilhelm Bleek and Lucy Lloyd. Cape Town: Jacana. 75-89.

Penn, N. 2005. The Forgotten Frontier: Colonist and Khoisan on the Cape's Northern Frontier in the 18th Century. Cape Town: Double Storey.

Schmidt, Sigrid. 1989. Catalogue of the Khoisan Folktales of Southern Africa. Hamburg: Helmut Buske Verlag.

Schultze, Leonhard. 1907. Aus Namaland und Kalahari. Bericht an die königlich Preussische Akademie der Wissenschaften zu Berlin über eine Forschungsreise im westlichen und zentralen Südafrika in den Jahren 1903-1905. Jena: Gustav Fischer.

Skotnes. P. 2007. Claim to the Country. The Archive of Wilhelm Bleek and Lucy Lloyd. Cape Town: Jacana.

Skotnes, P. et al (eds) 2007. The Digital Bleek and Lloyd. Available as an optical computer disk in Skotnes (2007), as well as online: $<$ http://lloydbleekcollection. cs.uct.ac.za/index.html.>

Wittenberg, H. 2012. Wilhelm Bleek and the Khoisan imagination: A study of censorship, genocide and colonial science. Journal of Southern African Studies 38(3): 667-679. 